\title{
Factors Causing Health and Safety Hazards in Construction Projects in Pakistan
}

\author{
AFTAB HAMEED MEMON*, MOHSIN ALI SOOMRO*, NOOR AHMED MEMON*, AND \\ MUSAWIR NAZEER ABASSI* \\ RECEIVED ON 14.03.2016 ACCEPTED ON 16.08.2016 \\ ABSTRACT
}

\begin{abstract}
In spite of technical advancements, construction industry in developing countries, including Pakistan, heavily relies upon manual labor and orthodox methods of construction. Such practices then give rise to safety issues to which all construction industry practitioners, end users and the contextual environment is vulnerable. Contrary to the utmost need of investigating the situation, 'safety in Pakistan construction industry' has received very less attention from the academia and industrial researchers as well. This paper takes the opportunity to investigate fundamental factors that give rise to safety issues in local construction industry. A set of 23 factors have been identified based on the literature review. A questionnaire survey is then conducted that has reflected the most significant factors inflicting upon the safety issues on construction sites. The analysis results of $\mathbf{4 9}$ questionnaire survey responses showed that most significant factors causing health and safety hazards in construction projects are poor safety awareness among firm's leadership, lack of technical guidance in performing construction operations, lack of technological innovation/ use to improve safety, lack of strictly defined operational procedures and poor safety awareness of project managers.
\end{abstract}

Key Words: Construction Safety, Exploratory Study, Factors, Questionnaire Survey, Pakistan.

\section{INTRODUCTION}

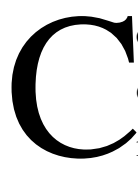

onstruction industry is complex and very much dynamic in nature, where each project is unique and different from other. A typical construction project consists of several phases such as project feasibility study, designing, planning, execution, decommissioning, demolition and clearance. All such phases entail various types of professions, other than typical construction works, which include HVAC (Heating Ventilation and Air-Conditioning), plumbing, electrical wiring, carpentry etc.In addition to a complex mixture of traditions and skills, a construction project involves multiple stakeholders among which most prominent are client, consultant and contractors.

Construction industry is a labor driven industry, where execution of work exposes workers to a variety of risks including prone to diseases; and therefore it is always reported for several problems [1]. Similar is the reason that construction sector is considered one of the toughest professions in the world. Among health and safety

* Department of Civil Engineering, Quaid-e-Awam University of Engineering, Science \& Technology, Nawabshah. 
problems in construction industry, occupational accidents have been reported in many countries around the world over many years and regarded as results of poor industry from health and safety standards implementation [2]. Compared to developed countries, the work related ailmentsin developing countries isstill an increasing problem.

Pakistan has the poor OHS (Occupational Health and Safety) legislation; even certain industrial sectors have not been included neither in the labor policy nor in the OHS legislation. The current OHSlegislation related to industrial OHS in Pakistan has many discrepancies as it does not cover construction and agricultural sector Following this fact, it is found that that concerned law and regulation enforcement agencies lack interest in enforcing strict measures [3]. Consequently, most of the construction companies habitually follow reactionary approach rather than to develop pro-active measures to reduce health and safety risks for their employees.

Presence of a rigors safety program on construction work sites is immensely needed [4].Construction materials, tools, machinery and handling techniques all come with their own dangers and hence construction industry is prone to many hazards and accident potential. Therefore, construction practitioners are needed to adopt adequate safety programs designed to respond potential project as well as designed to self-initiate process to bring back safe state if predetermined conditions are violated.

Safety is a critical item on all construction projects for multiple reasons including protecting the welfare of employees, providing a safe work environment and controlling construction costs. Thus, it is vital to take necessary actions for improving OHS on construction sites and reduce health and safety hazards. For this, first step is to uncover the responsible factors causing health and safety hazards. Hence, this study is carried out to identify significant factors causing health and safety hazards in construction projects of Pakistan.

\section{SAFETY PERFORMANCE IN CONSTRUCTION PROJECTS}

Construction is a sensitive industry where several risks are associated with workplace. Negligence of employers also creates unnecessary risk in the projects. Thus, the construction organization is required to edify the workers for understanding and adopting proper safety precautions and the regulations. Further, Farooqui et. al. [5] highlighted that more exigent and hazardous working environment has been witnessed since the induction of the advanced technology although it has contributed positively to the industry production. It has resulted in increasing the frequency of causing disability by injury or serious illness. The research work conducted byAhmed et. al. [6] showed that majority of the construction workers face serious consequences in terms of disability, injuries or health issues. In Australia, 256 people were seriously injured between 1989 and 1992 on construction sites [7] while in 2012, fatality rate was recorded as 4.11 which was the third highest fatality rate of all the industries [8] and in 2013, $1 \%$ of fatalities were incurred in construction industry [9]. The study conducted in china in 2000 showed that more than 3000 workers lose their lives yearly in work accidents as cited by Farooqui, et. al. [10]. In Hong Kong, 275 accident cases were reported for each 1,000 workers by 1994 which were increased to around 150 by year 2000 [7]. In 2014 in Hong Kong, 3538 accidents were observed, which included 38 fatalities [11] while in 2015, 3863 accidents including 43 fatalities were recorded in Hong Kong Construction industry [12]. Among the accidents occurring on construction sites in Hong Kong, major reason is identified as unsafe human behavior [13]. In Japan, 10 in every 1000 construction workers suffer an injury every year and accident rate in United Kingdom was recorded as around 50 in every 1000 workers [7]. 
Research work conducted for Egyptian construction industry highlighted that no formal procedures are not usually adopted for safety of workers but a fixed accident insurance costs is implemented [14]. In United States, 806 of 4628 total fatal work injuries and 71,730 not fatal injuries were recorded in construction industry. This high number of fatal and non-fatal accidents has motivated construction companies to find various novel approaches to reduce work-related accidents [15]. Overall one third of workplace fatalities in US occur in construction industry; while in Finnish construction industry the occurrence of fatalities is one fourth of overall fatalities occurring in the country [16]. Yi et. al.[17] reported that Korean construction industry occupied highest rate of fatalities among all the sectors. About 7\% of world's labour is occupied in construction industry and rate of fatalities occurring in construction industry is $30-40 \%$ of total fatalities [18].

Construction in developing countries, such as Pakistan and India, is more labor intensive that in the developed areas of the globe, involving 2.5-10 times as many workers per activity [10-19]. These accidents may sometimes cause death to the workers. The cost of the project is significantly affected by poor safety and consequential accidents. China about $8.5 \%$ of total cost of project was incurred upon the accidents during the execution of the construction projects [20]. In a studyof Palestinian and Gulf construction industry it was found that size and nature of the project were instrumental for the cost of the safety. She found that significant portion of managers sees safety is substantially contributing in cost increase. It is also found that cost of safety equipment is mentioned explicitly in the contract documents, despite the fact that total cost of accidents in commercial and housing construction reaches up to $7.9 \%$ at average with maximum capping of $15 \%$ in some projects [21]. Even in developed countries, such as United States, several OHS measures have been implemented but yet number of incidents and consequent loss is very high where about 700 workers die each year and approximately $\$ 15$ billion of monetary is faced in a year [22].

Though, safety seems on priority of project developers and associated consultants, but soon after construction works are commenced the focus is shifted towards meeting project deadlines; and then initial safety commitments are usually jeopardized. The traditional practice confirms, by virtue of contract, the availability of basic first aid accessories; however, the responsibility of safety practices in construct activities largely still rests with contractors. The same notion is confirmed by Farooqui et. al. $[5,10]$ in his study where he reported majority of accidents are caused by construction execution activities that include fall from height, head and eye injuries, struck and fall incidents etc. The available research identifies many factors, which simply increase accident probability. Such factors are 'poor safety knowledge and awareness among team leadership’, 'lack of training', 'reluctance to invest in safety equipments', 'vaguely defined and ill construction operations', 'poor condition of equipments' 'low level of education' and in last 'enforcement of safety regulations' [22,24]. As for the case of Pakistan construction industry, the level of enforcement of safety regulations is at its lowest level. Nevertheless, as a very little focus had been given to the local construction industry, majority of the factors responsible for bringing safety catastrophe are still laid in veil. Therefore, this research intends to lift such veil, and highlight the factors that prone construction personnel to the safety risk.

\section{RESEARCH METHODOLOGY}

The research methodology is comprised of four consecutive phases, i.e. (1) literature review, (2) identification of factors causing health and safety hazards, (3) questionnaire design and survey, and (4) statistical analysis of collected responses and drawing of results. 
In depth review of construction safety literature is performed to understand current trends and practices in preventing hazards in the construction. The literature review included publications in renowned research journals, field studies and reports by various governments and non-governmental organizations and statistical data published in the various forms of mass media. The detail of literature review is provided in previous sections.

The available literature on construction safety has reflected numerous publications citing a variety of factors that could inflict upon the safety in construction operations. The examples of such publications are at the reference $[2,4,8,26]$ etc. As this research has intended to focus the local construction industry, therefore, a specific search is made to identify the studies that could match more closely to the geographical objectives of this study. After evaluating numerous publications, finally the factors are barrowed from the publications at the references $[10,23,27]$. All of the three publications have focused construction projects in developing regions. Nevertheless, to develop a concise list of the factors that could illustrate specific domains influencing safety in the local construction projects, the borrowed factors are then analyzed, refined, consolidated and categorized to illustrate a comprehensive set of factors causing health and safety hazards in construction industry. Table 1 shows the final set of factors, which are further categorized in four domains to illustrate their roots.

TABLE 1. FACTORS INFLUENCING HEALTH AND SAFETY HAZARDS IN CONSTRUCTION INDUSTRY

\begin{tabular}{|c|c|}
\hline Category & Factors \\
\hline \multirow{7}{*}{ Personnel Knowledge and Professional Skills } & Poor safety awareness among firm's leadership \\
\hline & Poor safety awareness of project managers \\
\hline & Lack of safety training for labor and other employee \\
\hline & Lack of certified skilled labor \\
\hline & Poor safety conscientiousness of labors \\
\hline & Lack of experienced project managers \\
\hline & Low level education of labors \\
\hline Equipment Related & Lack of wearable protective equipment \\
\hline \multirow{11}{*}{ Operational Procedures } & Poor condition of equipments \\
\hline & Lack of technological innovation/use to improve safety \\
\hline & Ineffective safety regulations on construct ion site \\
\hline & Lack of strictly defined operational procedures \\
\hline & Lack of protection in material transportation \\
\hline & Lack of technical guidance in performing construction operations \\
\hline & Lack of rigorous enforcement of safety regulations \\
\hline & Shortage of safety management manuals on construction site \\
\hline & Lack of organizational commitment for safety assurance of employees \\
\hline & Lack of protection in material storage \\
\hline & Lack of onsite first-aid measures \\
\hline \multirow{4}{*}{ Organizational Regulations } & Reluctance to input resources for safety measures \\
\hline & Lack of safety regulations \\
\hline & Lack of teamwork spirits \\
\hline & Excessive overtime work for labor \\
\hline
\end{tabular}

Mehran University Research Journal of Engineering \& Technology, Volume 36, No. 3, July, 2017 [p-ISSN: 0254-7821, e-ISSN: 2413-7219] 
A questionnaire is then developed to assess the factors' significance in the local construction industry. A five point Likert scale is used to record responses on the designed questionnaire. The five points represented as ' 1 ' for 'not significant', '2' for ‘slightly significant', ‘3' for 'moderately significant', '4' for 'very significant' and '5' for 'extremely significant'.

The questionnaire survey isperformed in person by the visiting the construction sites and getting questionnaire forms filled by project personnel. This study has taken three categories of respondents, i.e. (1) management level (2) project engineers and (3) skilled labor/supervisors. All the three categories are taken from the three basic stakeholders of construction industry, i.e. client, contractor and consulting engineers. The surveyors approached various types of construction projects (mostly, housing and infrastructure projects) in the vicinity of Sindh and Punjab provinces of Pakistan.

Collected filled questionnairesare then digitized by using a spreadsheet software package 'Microsoft Excel 2014'; and then the digitized data set is analyzed using statistical SPSS (Software Package for Social Scientists) version 20. To achieve significance index of the factors, the five point Likert scale responses are normalized at 100 point scale. Zhang [25] presented a simplified formula to convert likert scale to achieve significance index in the form of 100 point scale.

$$
\text { Significance Index }=\frac{\mathrm{R}_{\mathrm{i} 1} \times 20+\mathrm{R}_{\mathrm{i} 2} \times 40+\mathrm{R}_{\mathrm{i} 3} \times 60+\mathrm{R}_{\mathrm{i} 4} \times 80+\mathrm{R}_{\mathrm{i} 5} \times 100}{\mathrm{R}_{\mathrm{i} 1}+\mathrm{R}_{\mathrm{i} 2}+\mathrm{R}_{\mathrm{i} 3}+\mathrm{R}_{\mathrm{i} 4}+\mathrm{R}_{\mathrm{i} 5}}
$$

Here $\mathrm{R}_{\mathrm{i} 1}$ for the number of responses as " 1 ” for $\mathrm{i}^{\text {th }}$ failure drivers; $\mathrm{R}_{\mathrm{i} 2}$ for the number of responses as " 2 " for $\mathrm{i}^{\text {th }}$ failure drivers; $\mathrm{R}_{\mathrm{i} 3}$ for the number of responses as “ 3 ” for $\mathrm{i}^{\text {th }}$ failure drivers; $\mathrm{R}_{\mathrm{i} 4}$ for the number of responses as “ 4 ” for $\mathrm{i}^{\text {th }}$ failure drivers; $\mathrm{R}_{\mathrm{i} 5}$ for the number of responses as “ 5 ” for $\mathrm{i}^{\text {th }}$ failure drivers.

\section{RESPONDENTS' DEMOGRAPHICS}

A total of 49 completed questionnaires arecollected from 20 different construction sites.Among collected responses 43\% (i.e.21 respondents) are from owner’s organization, 8\% (i.e. 4 respondents) are from consulting engineers and remaining 49\% (i.e. 24 respondents) are from the personnel attached with contractors. Table 2 shows the respondents’ demographic.

All of the respondents possess sufficient experience to illustrate rigors opinion on the factors identified by the authors. Out of total 49 respondents, only 7 are having a low experience of 5 years and below. Half of the respondents fall in the experience categories of 6-10 and 11-15 years. Nevertheless, the $16 \%$ of the sample population possess experience as high as above 25 years. Such rich experience depicts the quality of the collected responses. Fig. 1 shows the respondents' experience distribution.

TABLE 2. RESPONDENT'S DEMOGRAPHIC

\begin{tabular}{|c|c|c|c|c|}
\hline & \multicolumn{4}{|c|}{ Type of Organization } \\
\cline { 2 - 5 } & Client & Consultants & Contractor & Total \\
\hline Managing Director & 1 & 0 & 2 & 3 \\
\hline Project Engineer & 14 & 3 & 15 & 32 \\
\hline Skilled Labor & 6 & 1 & 7 & 14 \\
\hline Total & 21 & 4 & 24 & 49 \\
\hline
\end{tabular}

Mehran University Research Journal of Engineering \& Technology, Volume 36, No. 3, July, 2017 [p-ISSN: 0254-7821, e-ISSN: 2413-7219] 


\section{RANKING OF the FACTORS CAUSING HELTH AND SAFETY HAZARDS}

Equation (1) is used to normalize the responses recorded on Likert scale. Table 3 shows the factors along with their recorded significance. The factors are ranked with respect to their significance level.

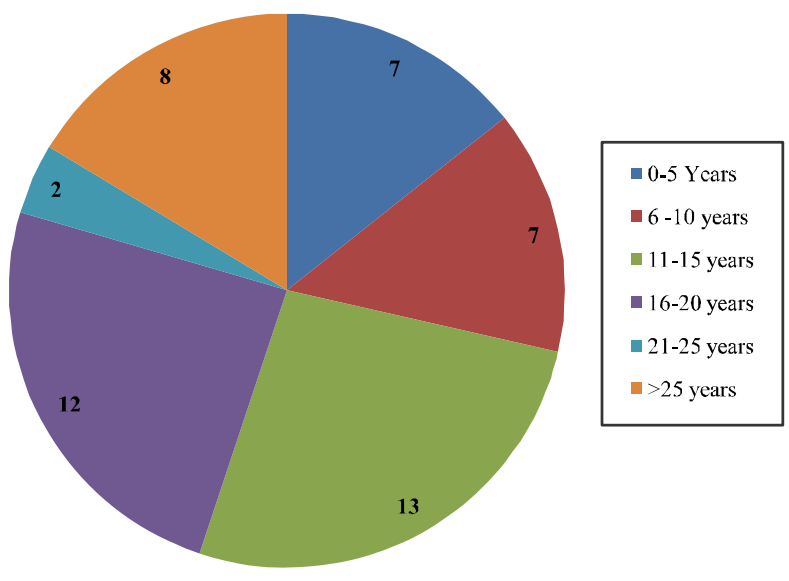

FIG. 1. RESPONDENTS EXPERIENCE
It is to be noted that most of the factors (i.e. up to ranked $11^{\text {th }}$ out of maximum ranked at $18^{\text {th }}$ ) have scored above 80 on the SI (Significant Index). The top five factors are associated with personnel knowledge and their professional skills and with operation procedures adopted on-site. The number $4^{\text {th }}$ ranked factors are construction equipment related. It is to be noted that both of these factors have scored above 87 on the significant scale, while the top scoring factor have gain 90.20 on the same index, and therefore may be regarded as highly significant. Factors ranked $5-6^{\text {th }}$ also depicts the impact of low personnel knowledge on understanding job nature the consequent rise of safety concerns. Similar trend is seen through Table 3, where the organizational procedures and personnel knowledge and skills are apparently taking higher ranks. The factors associated with organizational regulations have scored quite low in comparison to other categories, apart from 'lack of safety regulations' that has secured the $10^{\text {th }}$ rank.

TABLE 3. SIGNIFICANCE OF FACTORS CAUSING HEALTH AND SAFETY HAZARDS IN LOCAL CONSTRUCTION INDUSTRY

\begin{tabular}{|c|c|c|c|c|c|c|c|c|}
\hline No. & Factor & 1 & 2 & 3 & 4 & 5 & SI $(\%)$ & Rank \\
\hline 1. & Poor safety awareness among firm's leadership & 0 & 0 & 6 & 12 & 31 & 90.20 & 1 \\
\hline 2. & Lack of technical guidance in performing construction operations & 0 & 0 & 6 & 17 & 26 & 88.16 & 2 \\
\hline 3. & Lack of technological innovation/ use to improve safety & 0 & 1 & 4 & 18 & 26 & 88.16 & 2 \\
\hline 4. & Lack of strictly defined operational procedures & 0 & 0 & 7 & 16 & 26 & 87.76 & 3 \\
\hline 5. & Poor safety awareness of project managers & 0 & 2 & 4 & 17 & 26 & 87.35 & 4 \\
\hline 6. & Poor condition of equipments & 0 & 0 & 6 & 19 & 24 & 87.35 & 4 \\
\hline 7. & Lack of wearable protective equipment & 1 & 2 & 2 & 17 & 27 & 87.35 & 4 \\
\hline 8. & Lack of safety training for labor and other employees & 1 & 1 & 3 & 23 & 21 & 85.31 & 5 \\
\hline 9. & Lack of experienced project managers & 0 & 1 & 6 & 21 & 21 & 85.31 & 5 \\
\hline 10. & Lack of certified skilled labor & 0 & 0 & 10 & 18 & 21 & 84.49 & 6 \\
\hline 11. & Ineffective safety regulations on construction site & 0 & 2 & 8 & 17 & 22 & 84.08 & 7 \\
\hline 12. & Lack of protection in material transportation & 1 & 1 & 7 & 18 & 22 & 84.08 & 7 \\
\hline 13. & Poor safety conscientiousness of labors & 0 & 2 & 7 & 20 & 20 & 83.67 & 8 \\
\hline 14. & Lack of rigorous enforcement of safety regulations & 0 & 2 & 6 & 25 & 16 & 82.45 & 9 \\
\hline 15. & Lack of safety regulations & 0 & 1 & 9 & 23 & 16 & 82.04 & 10 \\
\hline 16. & Reluctance to input resources for safety measures & 1 & 1 & 9 & 24 & 14 & 80.00 & 11 \\
\hline 17. & Lack of organizational commitment for safety assurance of employees & 1 & 0 & 13 & 20 & 15 & 79.59 & 12 \\
\hline 18. & Lack of teamwork spirits & 1 & 1 & 17 & 13 & 17 & 77.96 & 13 \\
\hline 19. & Lack of onsite first-aid measures & 0 & 0 & 18 & 18 & 12 & 77.50 & 14 \\
\hline 20. & Shortage of safety management manuals on construction site & 1 & 1 & 17 & 19 & 11 & 75.51 & 15 \\
\hline 21. & Lack of protection in material storage & 1 & 2 & 14 & 23 & 9 & 75.10 & 16 \\
\hline 22. & Low education level of workers & 2 & 1 & 17 & 20 & 8 & 72.92 & 17 \\
\hline 23. & Excessive overtime work for labor & 4 & 3 & 21 & 13 & 8 & 67.35 & 18 \\
\hline
\end{tabular}




\section{CROSS CATEGORICALANALYSIS OF THE IDENTIFIED FACTORS}

This section attempts to assess the perception of basic stakeholders in construction process. The three categories of stake holders are; i.e. (1) Client, (2) Consultants and (3) Contractors. Cross categorical analysis is performed by means of developing individual significance index for each stakeholder responses. Table 4 shows the individual SI for each category of stakeholder. Practically, it is quite possible for a respondent to possess experience of other categories, nevertheless. Forthe sake of simplicity, this research has considered that respondents are representing their category of their current affiliation. This cross categorical analysis will help in understanding varied stakeholders' perception towards factors causing health and safety hazards.
Clients see 'lack of wearable equipment' as most significant factor causing health and safety hazards. The consultants seem to agree with them by ranking same factor on $2^{\text {nd }}$ rank; however, the contractors have shown bigger difference in its place by ranking it on $10^{\text {th }}$. Nevertheless, all three stakeholders seem to be agreeing with each-other on ranking of factors numbered from $2^{\text {nd }}$ to $5^{\text {th }}$. Contractors are showing their difference on sixth factor "ineffective safety regulations on site" by ranking it on $11^{\text {th}}$, while clients and contractors have ranked it on $5^{\text {th }}$ and $4^{\text {th }}$ respectively. From this trend of ranking by the stakeholders it is shown that contractors are either overly optimistic about their onsite safety arrangements or they consider other factors associated with clients and consultants more prone of trigging health and safety hazards. Such as for 'Lack of strictly defined operational procedures' and Lack of technical guidance in performing

TABLE 4. RANKING OF THE FACTORS BASED ON RESPONDENT GROUPS

\begin{tabular}{|c|c|c|c|c|c|c|c|}
\hline \multirow{3}{*}{ No. } & \multirow{3}{*}{ Factors } & \multicolumn{6}{|c|}{ Ranking of Different Groups of Respondents } \\
\hline & & \multicolumn{2}{|c|}{ Client } & \multicolumn{2}{|c|}{ Consultant } & \multicolumn{2}{|c|}{ Contractor } \\
\hline & & SI $(\%)$ & Rank & SI $(\%)$ & Rank & SI $(\%)$ & Rank \\
\hline 1. & Lack of wearable protective equipment & 94.29 & 1 & 85.00 & 2 & 81.67 & 10 \\
\hline 2. & Poor safety awareness among firm's leadership & 92.38 & 2 & 75.00 & 4 & 90.83 & 1 \\
\hline 3. & Lack of technological innovation/ use to improve safety & 91.43 & 3 & 75.00 & 4 & 87.50 & 4 \\
\hline 4. & Poor safety awareness of project managers & 90.48 & 4 & 85.00 & 2 & 86.67 & 5 \\
\hline 5. & Poor condition of equipments & 89.52 & 5 & 85.00 & 2 & 85.83 & 6 \\
\hline 6. & Ineffective safety regulations on construction site & 89.52 & 5 & 75.00 & 4 & 80.83 & 11 \\
\hline 7. & Lack of strictly defined operational procedures & 88.57 & 6 & 75.00 & 4 & 89.17 & 2 \\
\hline 8. & Lack of protection in material transportation & 88.57 & 6 & 80.00 & 3 & 80.83 & 11 \\
\hline 9. & Lack of safety training for labor and other employee & 87.62 & 7 & 70.00 & 5 & 85.83 & 6 \\
\hline 10. & Lack of technical guidance in performing construction operations & 87.62 & 7 & 90.00 & 1 & 88.33 & 3 \\
\hline 11. & Lack of certified skilled labor & 86.67 & 7 & 75.00 & 4 & 84.17 & 8 \\
\hline 12. & Poor safety conscientiousness of labors & 86.67 & 7 & 85.00 & 2 & 80.83 & 11 \\
\hline 13. & Lack of rigorous enforcement of safety regulations & 85.71 & 8 & 75.00 & 4 & 80.83 & 11 \\
\hline 14. & Lack of experienced project managers & 85.71 & 8 & 75.00 & 4 & 85.00 & 7 \\
\hline 15. & Reluctance to input resources for safety measures & 82.86 & 9 & 55.00 & 7 & 79.17 & 12 \\
\hline 16. & Lack of safety regulations & 81.90 & 10 & 75.00 & 4 & 83.33 & 9 \\
\hline 17. & Lack of teamwork spirit & 81.90 & 10 & 80.00 & 3 & 74.17 & 14 \\
\hline 18. & Shortage of safety management manuals on construction site & 80.95 & 11 & 60.00 & 6 & 73.33 & 15 \\
\hline 19. & Lack of organizational commitment for safety assurance of employees & 80.00 & 12 & 85.00 & 2 & 78.33 & 13 \\
\hline 20. & Lack of protection in material storage & 77.14 & 13 & 75.00 & 4 & 73.33 & 15 \\
\hline 21. & Lack of onsite first-aid measures & 71.43 & 14 & 75.00 & 4 & 79.17 & 12 \\
\hline
\end{tabular}

Mehran University Research Journal of Engineering \& Technology, Volume 36, No. 3, July, 2017 [p-ISSN: 0254-7821, e-ISSN: 2413-7219] 
construction operations, which are ranked $3^{\text {rd }}$ and $4^{\text {th }}$ by the contactors, while the same are ranked as $6^{\text {th }}$ and $7^{\text {th }}$ by the clients. Nevertheless, the consultants have ranked 'Lack of technical guidance in performing construction operations' as the most significant factor with the score of 90 on SI, which makes its among most significant factor. It is to be noted that the same factor is ranked $2^{\text {nd }}$ in general SI; i.e. Table 3. Another notable difference on ranking, with similar trend, is depicted at $8^{\text {th }}, 12^{\text {th }}$ and $13^{\text {th }}$ numbered factors. These three factors are apparently associated with the contractors, where they seem to differ with the ranking reflected by the clients and consultants. For other remaining factors, stakeholders seem agree with each other with slight differences on the rankings.

Equation (2) is developed to indicate SI of the each category of the identified factors. The Equation (2) is basically indicating average SI score by each factor in respective category (Table 5).

Categpry Significance Index $=\sum_{\mathrm{i}=0}^{100} \frac{\mathrm{F}_{\mathrm{si}}}{\mathrm{nF}}$

Where $F_{s i}$ is the S.I score of the $\mathrm{i}^{\text {th }}$ factor, $n F$ is the total number factors in the category.

The category SI shows that the construction equipment related factors are the most significant to raise health and safety issues. Clients and consultants are have reflected the similar notion, while the contractors have differed with slight higher scoring on personal knowledge and professional skills. It shows that contracts believe that professional skills of the construction work force plays most important role to trigger or to prevent any potential health and safety hazards. Clients and contractors both have ranked 'personal knowledge and professional skills' next to 'construction equipment related'. Factor categories of 'operational procedures' and 'organizational regulations' are universally ranked as $3^{\text {rd }}$ and $4^{\text {th }}$ by all stakeholders.

\section{CONCLUSIONS}

This paper has attempted to explore factors causing health and safety hazards in Pakistani construction industry. In pursuit of the objective, a thorough literature review has been conducted to explore previous research and studies in other parts of the world. The literature review revealed numerous factors that have been identified as raising health and safety hazards. All identified factors are then analyzed, coded and consolidated to reflect generic domains influencing health and safety hazards. A total of 23 factors are then finalized in four categories, i.e. (1) personnel knowledge and professional skills, (2) equipment related, (3) operational procedure and (4) organizational regulations. Among these four, 'personal knowledge and professional skills' and 'equipment related' categories have been unanimously ranked top by the respondents from construction industry stakeholders. The category of factors associated with 'organizational regulations' have been ranked lowest among four. Among all three categories of stakeholders, clients and consultants seems agreeing on the ranking of the factors up to high extent; while the contractors have found differing at many rankings. From the rankings, evaluated by this study it is concluded that the contractor's perception on triggering health and safety hazards is more towards operational procedures defined by the other two stakeholders.

TABLE 5. SIGNIFICANCE INDEX OF CATEGORIES OF FACTORS

\begin{tabular}{|c|c|c|c|c|}
\hline Factor Category & General SI (\%) & Client SI (\%) & Consultant SI (\%) & Contractor SI (\%) \\
\hline Personnel Knowledge and Professional Skills & 84.18 & 85.85 & 77.86 & 83.93 \\
\hline Equipment Related & 87.35 & 91.91 & 85.00 & 83.75 \\
\hline Operational Procedure & 82.53 & 84.55 & 75.56 & 81.48 \\
\hline Organizational Regulations & 77.39 & 78.86 & 75.00 & 76.00 \\
\hline
\end{tabular}

Mehran University Research Journal of Engineering \& Technology, Volume 36, No. 3, July, 2017 [p-ISSN: 0254-7821, e-ISSN: 2413-7219] 
The top ranking of the 'personal knowledge and professional skills' and 'equipment related' categories have indicated a dire need of labor training and strict equipment inspection. It is a sad fact that, in Pakistan, 'safety' standards have never taken place as a priority as it is in other manufacturing industries. The local construction industry still dominates with the less educated labor and sub-contractors, whose mere focus is profit than to do the safe job. The same notion is clearly evident from the rankings given by the respondents representing contractors, where safety parameters, availability of safety equipments etc., are among the lowest of the rank. It is, therefore, suggested that strict safety protocols may be incorporated in the prevailing construction law, and must be firmly regulated. Negligence to such protocols may then be heavily fined by the law enforcement agencies. A minimum education or training must be mandatory for the labors and other associated staff. Such training may be organized by the contractors at their camps. In the last, insurance companies may link all such requirements as a mandatory while insuring local construction projects; and the cases fails to do so may not be entertained for any claims.

\section{ACKNOWLEDGEMENT}

The authors are thankful to the Department of Civil Engineering, Quaid-e-Awam University of Engineering, Science \& Technology, Nawabshah, Pakistan, for providing necessary financial and other support to complete this studh.

\section{REFERENCES}

[1] Lazarevic, S.P., and Perry, M., "Occupational Health and Safety Shortcomings in the Australian Construction Industry [Online]”, Working Paper, Department of Management, Monash University [ISSN: 1327-5216], Available at: <http://arrow.monash.edu/vital/access/ services/Download/monash:2521/DOC> [Accessed on December 21, 2015], 2004.
[2] Eurostat, "Health \& Safety at Work Statistics”, Eurostat, available at:< http://ec.europa.eu/eurostat/statisticsexplained/index.php/Accidents_at_work_statistics> [Accessed December 21, 2015], 2015.

[3] Riaz, H., "Occupational, Health Safety and Environment in Textiles”, Online Available at: <http:// iepkarachi.org.pk /O\% 20H\%20S\%20E\%20in\%20 Textile-\%20Ms.\%20Hafsa\% 20Ri az.pdf >Accessed December 21, 2015.

[4] Mohamed, S., "Scorecard Approach to Benchmarking Organizational Safety Culture in Construction”, Journal of Construction Engineering \& Management, Volume 129, No. 1, pp. 81-88, 2003.

Farooqui, R.U., Ahmed, S.M., and Panthi, K., "Developing Safety Culture in Pakistan Construction Industry - An Assessment of Perceptions and Practices among Construction Contractors”, Proceedings of $4 \mathrm{ht}$ International Conference on Construction in the 21st Century: Accelerating Innovation in Engineering, Management and Technology, Gold Coast, Australia, pp. 420-437, 2007.

[6] Ahmed, S.M., Kwan, C., Young, W.M., and Pui, C.H., "Site Safety Management in Hong Kong”, Journal of Management in Engineering, ASCE, Volume 16, No. 6, pp. 34-42, 2000.

[7] Rowlinson, S., "Hong Kong Construction - Safety Management and the Law”, Sweet \& Maxwell Asia, Causeway Bay, Hong Kong, 2003.

[8] Safe Work Australia, "Key Work Health and Safety Statistics, Australia 2014”, Available at http:// Www.safeworkaustralia.gov.au/sites/SWA/about/ Publications/Documents/841/Key-WHS-Statistics2014.pdf accessed on 15 June, 2016.

[9] Safe Work Australia, "Key Work Health and Safety Statistics, Australia 2015”, Available at http:// Www.safeworkaustralia.gov.au/sites/SWA/about/ Publications/Documents/910/key-whs-stat-2015.pdf accessed on 15 June, 2016. 
[10] Farooqui, R.U., Farrukh, A., and Rafeeqi, S.F.A., "Safety Performance in Construction Industry of Pakistan”,

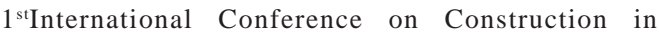
Developing Countries, Advancing and Integrating Construction Education, Research \& Practice, Karachi, Pakistan, August 4-5, 2008.

[11] Hong Kong Special Administrative Region, Labour Department, Occupational safety and health statistics Bulletin No. 15, 2015, Available at http:// www.labour.gov.hk/eng/osh/pdf/Bulletin2014.pdf, 2015.

[12] Hong Kong Special Administrative Region, Labour Department, Occupational Safety and Health Statistics 2015, Available athttp://www.labour.gov.hk/eng/osh/pdf/ OSH_Statistics_2015wy_EN.pdf accessed on 15 June, 2016.

[13] Li, H., Lu, M., Hsu, S.C., Gray, M., and Huang, T., "Proactive Behavior-Based Safety Management for Construction Safety Improvement”, Safety Science, Volume 75, pp. 107-117, 2015.

[14] Hassanein, A.G., and Hanna, R.S., "Safety Performance in the Egyptian Construction Industry", Journal of Construction Engineering and Management, Volume 134, No. 6, pp. 451-455, 2008.

Demirkesen, S., and Arditi, D., "Construction Safety Personnel's Perceptions of Safety Training Practices", International Journal of Project Management, Volume 33, pp. 1160-1169, 2015.

[16] Zhang, S., Sulankivi, K., Kiviniemi, M., Romo, I., Eastman, C.M., and Teizer, J., "BIM-Based Fall Hazard Identification and Prevention in Construction Safety Planning”, Safety Science, Volume 72, pp. 31-45, 2015

[17] Yi, J.S., Kim, Y.W., Kim, K.A., and Koo, B., “A Suggested Color Scheme for Reducing Perception-Related Accidents on Construction Work Sites”, Accident Analysis \& Prevention, Volume 48, No. 9, pp. 185-192, 2012.

[18] Sunindijo, R., and Zou, P., "Political Skill for Developing Construction Safety Climate”, Journal of Construction Engineering and Management, Volume 138, No. 5, pp. 605-612, 2012.
Koehn, E., Kothari, R.K., and Pan, C., "Safety in Developing Countries: Professional and Bureaucratic Problems”, Journal of Construction Engineering and Management, Volume 121, No. 3, pp. 261-265, 1995.

Godwin, I.I., "Effect of Mechanization on Occupational Health and Safety performance in the Nigerian Construction Industry”, Journal of Construction in Developing Countries, 2011.

[21] Hassouna, M.A., "Improving Safety Performance in Construction Projects in Gaza Strip”, Thesis, 1998 (Available at library.iugaza.edu.ps/Thesis/65061.pdf, 2005).

Tam C.M., Zeng S.X., and Deng Z.M., "Identifying Elements of Poor Construction Safety Management in China”, Safety Science, Volume 42, pp. 569-586, 2004.

Abdul Rahim, A.H., MuhdZaimi, A.M., and Singh, B., "Causes of Accidents at Construction Sites", Malaysian Journal of Civil Engineering, Volume 20, No. 2, pp. 242-259, 2008.

[25] Xueqing, Z., "Critical Success Factors for Public-Private Partnerships in Infrastructure Development”, Journal of Construction Engineering and Management, Volume 131, No. 1, pp. 3-14, 2005.

[26] Choudhry, R.M., and Dongping, F., "Why Operatives Engage in Unsafe Work Behavior: Investigating Factors on Construction Sites”, Safety Science, Volume 46, No. 4,pp. 566-584, 2008.

[27] Ismail, Z., Samad, D., and Zakaria, H., "Factors Influencing the Implementation of a Safety Management System for Construction Sites”, Safety Science, Volume 50, No. 3,pp. 418-423, 2012. 